\title{
Relationship between Level of Stress and Social Support among Parents of Children with Cerebral Palsy
}

\author{
Noor Amiera Alias, Nur Khairun Amani Razali Azizan, Noor Azliyana Azizan \\ Faculty of Health Sciences, \\ Universiti Teknologi MARA, Selangor, Malaysia
}

nooramiera@uitm.edu.my, khai.amani912@gmail.com, noorazliyanaazizan@gmail.com Tel: $03-32584366$

\begin{abstract}
Social support helps prevent and decrease the stressful situation of the family's experience in providing care to children with cerebral palsy. Thus, this study aims to determine the significant relationship between social support and the level of stress among parents of children with cerebral palsy. The study revealed that the majority of the parents with cerebral palsy children who had high stress levels had perceived low social support. Therefore, this study may provide a guideline to the health professional to deliver support to assist the best adaptation in facing the issues.
\end{abstract}

Keywords: Parents; Cerebral Palsy; Social support; Stress

eISSN: 2398-4287C 2020. The Authors. Published for AMER ABRA cE-Bs by e-International Publishing House, Ltd., UK. This is an open access article under the CC BYNC-ND license (http://creativecommons.org/licenses/by-nc-nd/4.0/). Peer-review under responsibility of AMER (Association of Malaysian Environment-Behaviour Researchers), ABRA (Association of Behavioural Researchers on Asians) and cE-Bs (Centre for Environment-Behaviour Studies), Faculty of Architecture, Planning \& Surveying, Universiti Teknologi MARA, Malaysia. DOI: https://doi.org/10.21834/ebpj.v5i14.2187

\subsection{Introduction}

Cerebral palsy is known as a non-progressive condition. There is an injury or abnormalities in the brain in fetal or child development until the second year of postnatal life (Polita \& Tacla, 2014). According to previous studies, children with cerebral palsy were around $0.2 \%$ worldwide (Nelson \& Blair, 2015). The sign of motor and posture for cerebral palsy is mostly associated with problems in terms of perception, visual, communication, and mental, which influence daily living activities (Badia et al., 2016). Most children with cerebral palsy may require extra care and attention from caregivers due to their disabilities. Some of the severe cases may total dependent on mobility, self-care, and social participation. The severity of the condition affects not only the children but also caregivers. The study was revealed that parents of children with typically developed tend to get high-stress levels (Anthony et al., 2005). The parents with developmental disorders children, like, intellectual disabilities, autism including cerebral palsy are also tend to experience higher stress levels (Baker et al., 2003; Glenn et al., 2009). The parents who have to take care of children with cerebral palsy have been facing physical and psychological health challenges. Psychological health includes stress and emotional imbalance in handling children with cerebral palsy.

The perception of parents about the imbalance between the parent demands and resources that are available is considered as parental stress (Raphael, Zhang, Liu, \& Giardino, 2010), and it was found that the depression or stress is mostly coming from parents with children of cerebral palsy (Masterson, 2011). Previously, it was revealed that having support from family and friends has a tremendous impact on the level of stress and satisfaction of life among the parents, compared to support from spouses or partners (Wang, Huang, \& Kong, 2017). The study findings were correlated with the results from another research, which revealed, friend and family support were two of the crucial variables that contributed to the satisfaction of life in families in having people with disabilities, such as cerebral palsy (Kokorić et al., 2012). This indicates that support from family and friends have the same crucial roles in improving the satisfaction of life among mothers, especially the ones that have high-stress levels.

eISSN: 2398-4287@ 2020. The Authors. Published for AMER ABRA cE-Bs by e-International Publishing House, Ltd., UK. This is an open access article under the CC BYNC-ND license (http://creativecommons.org/licenses/by-nc-nd/4.0). Peer-review under responsibility of AMER (Association of Malaysian Environment-Behaviour Researchers), ABRA (Association of Behavioural Researchers on Asians) and cE-Bs (Centre for Environment-Behaviour Studies), Faculty of Architecture, Planning \& Surveying, Universiti Teknologi MARA, Malaysia.

DOI: https://doi.org/10.21834/ebpj.v5i14.2187 
However, children with cerebral palsy with severe disabilities were associated with a high level of stress among the parents and linked to the low level of social support from others such as family members, friends, and significant others (Al-Gamal, \& Long, 2012). Although some studies reported that parents of children with physical disabilities were at higher risk of poor mental health, most of the studies have been conducted in Western countries. As suggested by a study done by Lima, Cardoso, and Silva (2016), the authors stated that it is crucial for next future studies to examine how the mental health of the parents of children with cerebral palsy, stress levels, and social support among the parents of cerebral palsy children could be associated in the various settings. Furthermore, there is a lack of researches that has been conducted on social support and stress among parents who are having cerebral palsy children in Malaysia. Therefore, this study aims to examine the significant relationship between social support and the level of stress among parents of children with cerebral palsy.

\subsection{Literature review}

Health in physical and mental for parents with children of cerebral palsy was found to be unsatisfied as evidenced by symptoms like depression, stress, pain at the muscle, and decreased life quality (Freitas, Rocha, \& Haase, 2014). This showed that the risk of poor mental health is easily exposed to parents of cerebral palsy children, and the most crucial factor affecting the mental health of the parents is perceived by parental distress (Hung, $\mathrm{Wu}, \& \mathrm{Wu}, 2010$ ).

The higher levels of stress of the parents associated with poor mental health decreased life quality, and need more significant support from others such as family, spouse, and friends (Al-Gamal \& Long, 2013). However, social support which is known as the resources of psychological and material that found it is support for both father and mother via his or her interpersonal relationships (Lima, Cardoso, \& Silva, 2016). It is reasonable assistance, either tangible assistance such as money and food, or intangible assistance, such as verbal and emotional advice and motivation. It helps to avoid or decrease the stressful situation experienced by the parents who are having children with cerebral palsy, as the absence of social support can bring the feeling of neglect, anger, or sad among the parents who give a negative effect to the experience for the family (Polita, \& Tacla, 2014).

Moreover, it is also one of the most frequent variables that examine the life satisfaction as several previous studies found that the higher the social support perceived by the parents who are having cerebral palsy children, the higher the satisfaction of life for the parents (Wang, Huang, \& Kong, 2017). The previous study also found that mothers having children with cerebral palsy perceived less of family support, had a poor quality of life in marriage, and need more social support from others, especially from their partner, family members, and friends (Martinac \& Ljubesic, 2009). Previously, the researches found the correlation between the levels of stress among parents and social support perceived by them. Negative associations were found among mothers who have cerebral palsy children (Jeong et al., 2013). The lower the perceived social support among parents who are having cerebral palsy children, the higher the stress levels among the parents. These findings suggest that the degree of stress of the parents and social support are highly related to each other among the parents, mothers, and fathers who are having cerebral palsy children (Wang, Huang \& Kong, 2017).

\subsection{Methodology}

The cross-sectional study design has been conducted in Selangor, Spastic Children's Association of Selangor \& Federal Territory (SCAS\&FT), which involves parents with cerebral palsy children. The SCAS\&FT was chosen for this study as it is the largest school for children with cerebral palsy in Malaysia. It caters to about 200 children who live in Selangor and the Federal Territory, which are the most densely populated states of Malaysia, consisting of almost four million people.

Furthermore, the study also was conducted through media social, which is Facebook, Alliance of Children with Cerebral Palsy (GAPS), to get information about the levels of stress and social support among parents of children with cerebral palsy. A purposive sampling method was used to recruit sixty parents who are having children with Cerebral Palsy. This study's inclusion criteria are the primary caregiver who is taking care of children with cerebral palsy at the age of 1 to 12 years old. The caregivers also have a good cognitive function and mental health and able to understand English to complete the instruments. In the meanwhile, the children who have any other conditions as comorbidities such as autism spectrum disorder, genetic syndromes or mental disorders, and other caregivers who do not comprise with inclusion criteria have been excluded.

The Perceived Stress Scale (PSS) was used to identify stress levels among caregivers, while the Multidimensional Scale of Perceived Social Support (MSPSS) was used to identify social support towards caregivers. The level of stress and social support of parents of children with cerebral palsy were obtained by the Statistical Package for Social Science version 21 (SPSS 21). The data were analyzed using descriptive statistics (mean, standard deviation, frequency, and percentage). Bivariate correlation analysis will be taken to examine the significant relationship between social support and stress of parents of children with cerebral palsy. This step makes it possible to establish the viability of statistical analyses that detect the association between variables.

\subsection{Result}

\subsection{Socio demographic data}

\subsubsection{Parents}


The mean for the age of the 60 parents was $2.57(\mathrm{SD}=0.65)$ with a range of $25-34$ years. Of these, $53(88.3 \%)$ were mothers and 7 $(11.7 \%)$ were fathers with $(S D=0.32)$. While $57(95.0 \%)$ of the parents were still married, 2 of them were widowed $(3.3 \%)$, and another one has divorced $(1.7 \%)$ which $(S D=0.31)$. In Selangor, $44(73.3 \%)$ of the parents were Malay, eleven (18.3\%) were Chinese, and five $(8.3 \%)$ were Indian with $(S D=0.63)$. Seventeen of the parents were self-employed $(28.3 \%), 13$ parents work in government sector $(21.7 \%), 14$ parents work in the private sector $(23.3 \%)$ and 16 parents are unemployed $(26.7 \%)$. The mean for family monthly financial income is 3.73 (SD = 1.31), which range from RM2000 to RM3000.

\subsubsection{Children}

The children ranged in age from 1 to 12 years. There were $26(43.3 \%)$ girls and 34 (56.7\%) boys. Occupational therapists and teachers working in the centre helped in classifying the children's motor status. The parents also ticked down the level of gross motor function of cerebral palsy children in the questionnaire. In this study, $10(16.7 \%)$ children were classified as GMFCS(E\&R) level 1 (walks without limitations), 14 (23.3\%) as level 2 (walks with limitations), 3 (5.0\%) as level 3 (walks using a hand-held mobility device), 5 (8.3\%) as level 4 (may use power mobility) and $28(46.7 \%)$ as level 5 (transported in a manual wheelchair).

\subsection{Perceived stress among parents of children with cerebral palsy}

Forty -five parents reported a moderate level of stress which is $(75.0 \%)$. The mean score on the PSS was 20.35 (SD $=5.64)$ with a range of $14-26$ as in Table 1. While, $8.3 \%$ of the parents reported a high level of stress with a range of $27-40$. The most-reported stressor by ten parents $(16.7 \%)$ is upset because of something that happened unexpectedly, and they never felt confident about their ability to handle personal problems. Thirteen point three percent of parents, which 8 parents very often felt nervous and stressed. Besides, $55.0 \%$, of which 33 parents were sometimes angered because of things that were outside their control. $21.7 \%$, which 13 parents almost never felt that things were going on their way. Moreover, only $1.7 \%$ of parents, which one of them often felt difficulties were piling up so high that they could not overcome them.

Table 1. Mean score of total score PSS

\begin{tabular}{ccc}
\hline & Mean & Std. Deviation (SD)8 \\
\hline Total Score PSS & 20.35 & 5.644 \\
\hline
\end{tabular}

\subsection{Perceived social support among parents of children with cerebral palsy}

Table 2. Mean score of total score MSPSS

\begin{tabular}{lll}
\hline Perceived social support & Mean & SD \\
\hline Significant other & 2.43 & 0.65 \\
Family & 2.45 & 0.62 \\
Friend & 2.02 & 0.68 \\
Total score MSPSS & 4.88 & 1.35 \\
\hline
\end{tabular}

The mean score on the MSPSS was $4.88(S D=1.35)$ as detailed in Table 2. The results showed that family support subscale (mean $=$ $2.45, S D=0.62$ ) were ranked the highest means among all perceived social support subscale scores. While for significant other support subscales (mean $=2.43, \mathrm{SD}=0.65$ ) was the second rank of perceived social support. The friend support subscale was ranked the lowest (mean $=2.02, S D=0.68$ ). All the social support perceived by the parents of children with cerebral palsy considered as low social support as the range is between 1-2.9. 31 parents (51.7\%) got high perceived support from their family and significant other, while 13 $(21.7 \%)$ parents got low perceived social support from friends. Individual items analysis of MSPSS revealed that the most reported support by parents was item 3 (My family really tries to help me) where are $(28.3 \%) 17$ parents. The lowest reported score was for item 7 (I can count on my friends when things go wrong) and 12 (I can talk about my problems with my friends) where are (8.3\%) 5 parents.

\subsection{Significant relationship between social support and stress among parents of children with cerebral palsy}

Table 3. The significant relationship between perceived stress and perceived social support

\begin{tabular}{lcccc}
\hline & $\begin{array}{c}\text { Total score } \\
\text { MSPSS }\end{array}$ & Significant other & Family & Friend \\
\hline Level of stress & -0.154 & -0.097 & -0.096 & -0.147 \\
\hline
\end{tabular}


The results of the significant relationship between social support and stress among parents of children with cerebral palsy are shown in Table 3. The analysis shows that there was a significant negative correlation between level of stress and total social support scale, significant other scale, family-scale and friend scale $(r=-0.097, p<0.0005 ; r=-0.096, p<0.0005 ; r=-0.147, p<0.0005$, respectively). This indicates that parents with high levels of stress will perceive low social support from significant other, family members and also friends. So, the null hypothesis failed to accept.

\subsection{Discussion}

This study revealed that $75 \%$ of the parents reported moderate stress levels in taking care of the cerebral palsy children, and $8.3 \%$ of the parents are having a high level of stress. $26.7 \%$ of parents are reported as not working and entirely spend their time taking care of the cerebral palsy children. Most of them are the mother to the cerebral palsy children, which is consistent with research by Byrne, Hurley, Daly, and Cunningham (2010), who states that mothers begin to have remarkably low scoring than fathers in all dimensions; including mental health. Parents who spent long hours taking care of cerebral palsy children started to have decreased mental health than parents who provide less time to take care of children with cerebral palsy (Byrne, Hurley, Daly, \& Cunningham, 2010). In line with the study done by Raina et al. (2005), indicate that parents may become more exhausted and thus have a negative effect on their mental and physical health when giving more care and attention levels needed by cerebral palsy children. A study supports it found that very low health-related quality of life among mothers who have children with cerebral palsy(Meen, Alicia, \& Chang, 2019). Conversely, a previous study done by Button (2001) was the mother is having a high-stress level when partner support is considered a buffer to stress. This is because when mothers reported higher levels of helpfulness and identified the partner as a source of direct caregiving support for highly impaired children. Partner involvement in caregiving for more severely impaired children may disrupt caregiving routines established by mothers. Fathers may not know the specific caregiving techniques required, for example, to feed a cerebral palsy child or support independent exploration, and mothers may find it stressful to have fathers involved in that situation. However, the encouragement in social support may impact the coping resource for the caregivers to decrease their stress level (Manuel, 2003). Thus, it is still crucial to consider social support to help caregivers decrease their stressful issues.

Furthermore, this study found that parents received highest-ranked from family support. Followed by the second-ranked was significant other support, and the lowest-ranked of social support is from friend's support. The previous study supports this indicates that the help from the family and friends acted as significant roles in the relationship between stress levels and life satisfaction than partner support (Wang, Huang, Kong, 2017). Consistently, the previous study indicates that children with cerebral palsy families found their social support network within the family universe (Milbrath, Siqueira, Amestoy, \& Trindade, 2011), thus indicating that the family is a relevant source of care. In line with the finding of this study provides evidence that $51.7 \%$ of parents of cerebral palsy children got high social support from family and significant others. This is consistent with the previous research by Al-Gamal, and Long (2013), wherein cultures that value the integrity of the family, mutual support of significant others or partners, supplemented by other family members is crucial to help in coping of stress. Another study revealed that family support very depends on the availability of members in the family of cerebral palsy children and commonly focused on the responsibility of the mother. Family support is usually dependent on the core of the family itself, especially from older children.

In contrast, other family members, such as husband, grandparents, aunt, and mother-in-law, interact only in occasional events to provide the appropriate care (Dezoti, Alexandre, Freire, Mercês, \& Mazza, 2015). In another study, it is believed that parents tend to call upon God most of their time, as spirituality in order creates more positive thinking towards accepting their child's condition (Nimbalkar, Raithatha, Shah,\& Panchal,2014). So, it decreases the undesirable feelings and thoughts about the cerebral palsy children and can face the hard future promoted by cerebral palsy children (Dezoti, Alexandre, Freire, Mercês, \& Mazza, 2015).

In conclusion, family-centred services should assist social support and provide different skills to cope with the problems and needs of parents of children with cerebral palsy, with special attention to mothers (Basaran, Karadavut, Uneri, Balbaloglu, \& Atasoy, 2013). It is suggested that the family members play roles together in taking care of children with cerebral palsy. This study was found a correlation between stress level and social support perceived among parents. The parents who have cerebral palsy children show higher stress levels due to perceived low social support from significant others, family members, and friends. It is supported by the study done by Wang, Huang, \& Kong (2017) that parents showed more significant stress when they did not receive appropriate social support from their surrounding environment. In line with this finding, social relations can help to be more resilient to the disability of their children compared to others without social support perceived (Sipal, Schuengel, Voorman, Van Eck, \& Becher, 2010). Therefore, it is crucial to have social support for parents who have children with cerebral palsy in many sources, including family members, spouses, friends, therapists and many more.

\subsection{Conclusion \& Recommendations}

This study concludes that there is a relationship between social support and stress of parents who have children with cerebral palsy. Besides, it was revealed that the majority of the parents, who had higher stress levels, had perceived low social support from significant other, family members, and also friends. This study was done among a small sample size of parents in some regions of private rehabilitation centre. Thus, the finding of the study could not be generalized for this population. It is suggested that further research in larger sample size have diverse outcomes and qualitative research to highlight the source of stress and social support in-depth interview. However, it is crucial incorporating levels of stress among parents and the impacts in families with cerebral palsy children. The social support from three sources, such as significant other, family, and friend, are important to decrease stress level and achieve life 
satisfaction. Later, the health professional should recommend for a parent support group to deal with cerebral palsy to deliver effective rehabilitation process for children with cerebral palsy.

\section{Acknowledgements}

It is my pleasure to acknowledge all the participants, parents of children with cerebral palsy, cerebral palsy children, health professionals and representatives from Spastic Children's Association of Selangor \& Federal Territory (SCAS\&FT) who cooperate so willingly to make this research possible.

\section{References}

Al-Gamal, E., \& Long, T. (2013). Psychological distress and perceived support among Jordanian parents living with a child with cerebral palsy: A cross-sectional study. Scandinavian Journal of Caring Sciences, 27(3), 624-631.

Anthony, L.G., Anthony, B.J., Glanville, D.N., et al. (2005). The relationships between parenting stress, parenting behaviour and preschoolers' social competence and behaviour problems in the classroom. Infant and Child Development 14(2): 133-154.

Badia, M., Orgaz, B.M., Gomez, V.M., et al. (2016). Do environmental barriers affect the parentreported quality of life of children and adolescents with cerebral palsy? Research in Developmental Disabilities, 49-50: 312-321.

Baker, B.L., Mcintyre, L.L., Blacher, J, et al. (2002). Preschool children with and without developmental delay: Behavior problems and parenting stress over time. Journal of Intellectual Disability Research 47(4-5): 217-230.

Basaran, A., Karadavut, K.I., Uneri, S.O., Balbaloglu, O., \& Atasoy, N.(2013). The effect of having children with cerebral palsy on quality of life, burn-out, depression and anxiety scores: a comparative study. Eur J Phys Rehabil Med., 49(6):815- 22.

Button, S. (2001). Journal of Developmental and Physical Disabilities, 13(1), 61-81.

Byrne, M. B., Hurley, D. A., Daly, L., \& Cunningham, C. G. (2010). Health status of caregivers of children with cerebral palsy. Child: Care, Health and Development, 36(5), $696-702$.

Dezoti, A. P., Alexandre, A. M. C., Freire, M. H. de S., Mercês, N. N. A. das, \& Mazza, V. de A. (2015). Apoio social a famílias de crianças com paralisia cerebral. Acta Paulista de Enfermagem, 28(2), 172-176.

Freitas, P. M., Rocha, C. M., \& Haase, V. G. (2014). Análise dos preditores do estado psicológico das mães de crianças com paralisia cerebral [Analysis of predictors of psychological status of mothers of children with cerebral palsy]. Estudos e Pesquisas em Psicologia, 14(2), 453-473.

Glenn, S., Cunningham, C., Poole, H., Reeves, D., \& Weindling, M. (2009). Maternal parenting stress and its correlates in families with a young child with cerebral palsy. Child: Care, Health and Development, 35(1), 71-78.

Hung, J. W., Wu, Y. H., \& Wu, W.C., (2010). Mental Health of Parents Having Children With Physical Disabilities, 33(1), 10.

Jeong, Y.G., Jeong, Y.J. \& Bang, J. (2013). Effect of social support on parenting stress of Korean mothers of children with cerebral palsy. Journal of Physical Therapy Science. 25(10): 1339- 1342

Kokorić, S.B., Berc, G. \& Rusac, S. (2012). Satisfaction with life and informal and formal sources of support among people with disabilities. Drustvena Istrazivanja/Journal for General Social Issues 21(1): 19-38.

Lima, M. B. S., Cardoso, V. dos S., \& Silva, S. S. da C. (2016). Parental Stress and Social Support of Caregivers of Children With Cerebral Palsy, 26(64), $207-214$.

Manuel, J. (2003). Stress and Adaptation in Mothers of Children With Cerebral Palsy. Journal of Pediatric Psychology, 28(3), $197-201$.

Martinac Dorcic T, \& Ljubesic M. (2009). Psychological adjustment of parents of children with chronic disease. Drus Istraz [Social Research] 18, 1107-29.

Masterson, M.(2011). Chronic Sorrow in Mothers of Adult Children with Cerebral Palsy: An Exploratory Study. 2011. Ph.D. thesis.

Milbrath, V.M., Siqueira, H.C.H., Amestoy, S.C., \& Trindade, L.L.(2011). Redes de apoyo utilizadas por la familia cuando el niño nace com necessidades especiales. Evidentia. 2011; 8(36).

Nelson, K.B. \& Blair, E. (2015). Prenatal factors in singletons with cerebral palsy born at or near term. The New England. Journal of Medicine 373: 946-953.

Nimbalkar, S., Raithatha, S., Shah, R., Panchal, D.A. (2014). A qualitative study of psychosocial problems among parents of children with cerebral palsy attending two tertiary care hospitals in western India. ISRN Fam Med.

Meen Hye Lee, Alicia K Matthews, \& Chang Park (2019). Determinants of Health - related Quality of Life among mothers of children with cerebral palsy. Journal Pediatric Nursing, $44: 1-8$.

Polita, N. B., \& Tacla, M. T. G. M. (2014). Network and social support to families of children with cerebral palsy. Escola Anna Nery, 18(1), 75-81.

Raphael, J. L., Zhang, Y., Liu, H., \& Giardino, A. P. (2010). Parenting stress in U.S. families: Implications for pediatric health care utilization. Child: Care, Health, and Development, 36, 216-224. 
Raina, P., O'Donnell, M., Rosenbaum, P., Brehaut, J., Walter, S.D., Russell, D., Swinton, M., Zhu, B., \& Wood, E. (2005). The Health and Well-Being of Caregivers of Children With Cerebral Palsy. Pediatrics, 115(6), e626-e636.

Sipal, R. F., Schuengel, C., Voorman, J. M., Van Eck, M., \& Becher, J. G. (2010). Course of behaviour problems of children with cerebral palsy: the role of parental stress and support. Child: Care, Health and Development, 36(1), 74-84.

Wang, Y., Huang, Z., \& Kong, F. (2017). Parenting stress and life satisfaction in mothers of children with cerebral palsy: The mediating effect of social support. Journal of Health Psychology. 